\title{
LA PASIÓN Y EL RIGOR \\ DEL ANÁLISIS
}

JESÚS GÓMEZ SERRANO

Departamento de Historia/UAA

Pablo Latapí, Tiempo educativo mexicano, México, Universidad Autónoma de Aguascalientes/Universidad Nacional Autonoma de México, 1997, volumen IV, 224 pp.

$4 \mathrm{n}$ "El encuentro", uno de los cuentos que componen El informe de Brodie, Jorge Luis Borges escribió que "quien recorre los diarios cada mañana lo hace para el olvido o para el diálogo casual de esa tarde". Se trata de una dura sentencia, formulada, como era previsible, por un poeta que sostenía arduas sesiones de esgrima intelectual con los clásicos de varias literaturas; su conocimiento de ellos era tan íntimo que muchas veces no pudo resistir la tentación de convertirlos en personajes de sus breves y magistrales ensayos.

Alguien podría alegar que Borges era ciego y que, en consecuencia, la suya es una sentencia dictada por el despecho. Sin embargo, a mi me parece que en su apreciación, más allá de esa irreverente ironía que es uno de los sellos característicos de toda su prosa, hay mucho de verdad. Es sorprendente, por ejemplo, constatar la facilidad y la rapidez con la que envejecen los diarios y las revistas semanales de información. El diario se busca a primera hora de la mañana y de su lectura muchos miles de ciudadanos han hecho un ritual tan obligatorio como lo fue hace mucho el ir a misa, o como lo es para otros ver el futbol los domingos. Cualquiera que se asome a una de esas cafeterías de moda habrá advertido que en el paisaje predominan los caballeros acompañados de sendas tasas de café humeante y de un cúmulo de periódicos que a ratos resulta difícil manejar. Las señoras llegan un poco más tarde y por alguna extraña e incomprensible razón le dispensan 
a los periódicos mucha menor atención. Tal vez ellas prefieren a Borges.

Sin embargo, son muy pocos los que procuran los periódicos del día anterior y francamente raros los que buscan los de la semana o el mes pasados. Por supuesto, esos periódicos no se encuentran en el kiosko ni en el depósito: hay que esperar algunos años para consultarlos en el archivo, en calidad de fuentes aptas para el escudriñamiento del pasado. Son periódicos "viejos" (e inútiles) los de la semana pasada y se les da el correspondiente trato: limpiar vidrios en algunos casos, ser consumidos por el fuego en otros, lo que en cierta forma constituye la aplicación tardía de una sentencia justa: es tan deleznable su contenido.

No me importa por el momento discutir qué es lo que hace que los periódicos y las revistas se vuelvan viejos con tanta rapidez, sino preguntarme por los abusos del olvido. Nadie lamenta que las cabezas alarmistas, los comentarios tendenciosos, los pies de grabado equivocados y las fotos de los "villanos favoritos" se vayan a la basura, o que esperen con paciencia esa especie de día del juicio en el que las trompetas de los historiadores los llamen de nuevo a cuentas. Lo lamentable es que ese mismo olvido sea el destino de páginas que por muchas razones debieran conservarse frescas en la memoria.
Los artículos que semana a semana publica Pablo Latapí en Proceso son de ésos para los que la sentencia de Borges resulta injusta. Una buena pluma al servicio de causas nobles; un pensamiento riguroso que desnuda y aclara los hechos; un criterio independiente que vuelve confiable el análisis; una prosa clara y llana capaz de penetrar fenómenos de apariencia oscura; en suma, un académico que voluntariamente se ha exiliado de la torre de marfil y cuyos textos pueden ser leídos con provecho por cualquier ciudadano medianamente instruido.

Todo ello explica y sustenta la decisión de la UAA y la Coordinación de Humanidades de la UNAM de reunir en cuatro volúmenes los artículos de Latapí. Aunque con un ropaje menos informal que el original, las ideas siguen siendo las mismas, con la ventaja de que la valoración del conjunto permite atisbar mejor los campos en los que está centrado el interés del autor, las líneas maestras de su análisis y hasta sus obsesiones personales.

Cuando se leen en Proceso los artículos de Pablo Latapí se tiene siempre la sensación de escuchar a alguien que sabe ver más allá de los hechos inmediatos; que tiene la capacidad, la sabiduría y la generosidad necesarias para desmenuzarlos y mostrar sus implicaciones. Puesto que las suyas son propuestas que mantienen 
su vigencia, líneas dictadas por el patriotismo más sincero, una gran capacidad de análisis y una encomiable generosidad, resulta plenamente justificada y plausible la tarea de ordenar y publicar esas colaboraciones en libros. Es curioso, pero me parece que la vigencia que mantienen el análisis y las propuestas resulta mucho más clara o más contundente en el libro que en la revista. Es frecuente que los artículos periódicos de un autor se reúnan a título casi de curiosidad -textos "dispersos" se les llama-, pero en esta ocasión me parece claro que estamos delante de una visión unitaria y consistente de la sociedad, y en especial de la problemática educativa. En cierta forma, se nos ofrece completo un rompecabezas del que sólo conocíamos piezas aisladas. La consistencia y la vigencia del análisis se manifiestan con todo su vigor.

El libro que comento forma parte de una obra más amplia, que lleva como título general Tiempo educativo mexicano. El año pasado aparecieron los tres primeros tomos, consagrado el primero a la política y el acontecer educativos, el segundo a la calidad de la educación, el magisterio y la educación superior y el tercero al análisis de los valores, la política social, la rebelión indígena en Chiapas y el tema religioso. Los artículos recogidos en esos tres primeros tomos se publicaron originalmen- te en Proceso entre enero de 1992 y diciembre de 1995.

El cuarto tomo reúne las colaboraciones de Latapí publicadas entre enero de 1996 y los primeros meses de 1997. Como era de esperarse, los temas y las preocupaciones son los mismos que se aprecian en los tres primeros volúmenes, lo cual explica su articulación en cuatro grandes capítulos o apartados. Sin embargo, más que una reiteración encontramos una renovada capacidad de análisis centrada en los temas que conforman la preocupación vital y profesional del autor desde hace muchos años.

La prosa de Latapí tiene la doble virtud de ser clara y penetrante. Temas como el de la participación del magisterio en las tareas relacionadas con la modernización de la educación, que en los discursos y en las contiendas políticas parecen abstrusos, son reducidos por la pluma-bisturí de Latapí a sus elementos constitutivos, lo que los vuelve inteligibles. En ocasiones el autor no se contenta con proponer coordenadas de entendimiento de la problemática educativa nacional, sino que aventura propuestas concretas de solución. Sus ideas pueden o no ser compartidas, pero me parece encomiable que un analista dotado de las prendas morales e intelectuales de Latapí se interne en el bosque siempre espeso y confuso de las 
posibles soluciones que admiten los problemas de orden práctico.

Me parecen particularmente interesantes las ideas del autor sobre el financiamiento de la educación. En el contexto de la federalización de la enseñanza, lo que supone la transferencia a los estados de responsabilidades que tradicionalmente había hecho suyas el gobierno federal, se plantea el problema crucial de los recursos. Apoyado en un estudio que rebasa con mucho los límites periodísticos, Latapí sostiene que los actuales esquemas de financiamiento son injustos e ineficientes, a más de estar marcados por criterios o simples preferencias de carácter político. Ello ha implicado que algunos estados, genuinamente interesados en su desarrollo educativo, hayan tomado con bastante éxito la ofensiva, y que otros simplemente prefieran no destinar mayores recursos a ese rubro.

Aunque el autor reconoce que no posee una fórmula mágica para transparentar y eficientar la asignación de los recursos dedicados a la educación, hace notar que el análisis de la información disponible apunta en el sentido de que el gobierno federal, los gobiernos de los estados y el magisterio deben trabajar juntos en el hallazgo de nuevas fórmulas y consensos. Entre los criterios que según el autor de manera forzosa tendría que considerar una distribución justa de los recursos hay uno de carácter fiscal, otro de carácter hacendario y tres más propiamente educativos. Lo más importante, subraya Latapí, es demostrar que el tema del financiamiento puede utilizarse como un instrumento de planificación de la educación básica en todos los niveles (nacional, estatal, municipal y local).

En el mismo terreno de las propuestas concretas sorprende la atenta y respetuosa recomendación que le hace al Congreso de la Unión, en el sentido de que se pongan a trabajar en la confección de "un plan nacional de swaps" educativos. Mitad en broma y mitad en serio, pero partiendo del hecho cierto de que el servicio de la deuda consume anualmente miles de millones de dólares, equivalentes a varios puntos del PIB, que pudieran destinarse, con mucho mayor provecho para la nación, a ampliar la muy insuficiente partida del gasto público destinada a la educación, Latapí se pregunta si el interés de nuestros acreedores en la capacitación de la fuerza de trabajo mexicana y la elevación de los niveles educativos del país es sincero. Si es así, dice, sería razonable proponerles que se modere el servicio de la deuda y que cada peso ahorrado por ese concepto se emplee en educación. Con fina ironía Latapí sugiere que esa sería otra forma, acaso más productiva, de pagar lo 
que debemos y de asegurar que el país mejorará su capacidad productiva y se convertirá el día de mañana en un socio más confiable de las potencias económicas y financieras del planeta.

Otra de las preocupaciones centrales del autor es la carga moral y valoral de la educación. Casi no hay artículo en el que no haya una referencia a este tema, uno de los que evidentemente están más cerca de su mente y su corazón. Por eso no sorprenden los comentarios amplios y abiertamente favorables, hasta entusiasmados, que le dedica al informe de la Comisión Internacional sobre la Educación para el Siglo XXI. En dicho informe se reconocen sin ambages los límites del actual modelo de desarrollo económico, que son la causa de enormes desigualdades sociales y del irreversible deterioro del planeta. Reconocer ese hecho es mucho más importante de lo que sugieren las apariencias, pues implica que la educación debe definirse no como hasta ahora, "desde el punto de vista de su impacto en el crecimiento económico, sino desde la perspectiva más amplia del desarrollo humano".

El énfasis puesto por el informe en los valores humanos y la abierta crítica que se hace de "la visión funcionalista e instrumental de la educación" sorprenden al autor, quien comparte el rescate que se propone de la dimensión moral y cultural de la labor magisterial. Aunque en estos tiempos de librecambismo exacerbado y de feroz competencia comercial entre los países la afirmación puede parecer herética, el sistema educativo no persigue el propósito principal de formar mano de obra calificada, lo que significa tanto como hacer de los seres humanos simples engranes de ese complicado mecanismo de relojería que es la economía mundial. La educación tiene sin duda cierto sentido práctico y hasta utilitario, pero es necesario que esa premisa se considere en el contexto más amplio del desarrollo armónico de los individuos y las sociedades. Los seres humanos no son insumos del proceso productivo, sino la razón de ser del desarrollo económico. El hombre puede y debe aspirar a su plena realización, al desarrollo de su riqueza personal, a expresarse de maneras muy variadas y a asumir compromisos como individuo, como miembro de una familia y como ciudadano. En el contexto de esas aspiraciones, que bien merecen conceptuarse como la gran utopía del siglo XXI, la educación tiene una responsabilidad fundamental.

Tal vez -no lo sé- Pablo Latapí se haya sentido algunas veces como el Bautista, predicando a gritos en el desierto, agitándose con la misma gracia inútil con la que se mecen las cañas al viento. Sus libros son la reiteración de esa prédica y nada 
asegura que esta vez logre sacudir a la sociedad, la cual, como él mismo constata, prefiere entregarse gozosamente a la manipulación y la sistemática desinformación de las empresas dueñas de los sistemas nacionales de televisión. Pero es un hecho también, constatado por Latapí con algo que está a medio camino entre el prudente optimismo y el frío escepticismo académico, que los cambios se están dando, que no son despreciables los avances que se registran en el ámbito político, que las elecciones no son ya esa burda farsa con la que se nos humilló a lo largo de tantos años y que los canales abiertos a la participación ciudadana son cada vez más amplios. Sin duda estamos todavía muy lejos del México al que aspiramos y tenemos derecho, pero la perseverancia en el análisis crítico de Latapí y otros muchos estudiosos son una de esas luces que a veces distinguimos en el horizonte y nos ayudan a seguir adelante.

De manera marginal quisiera hacer una rápida alusión a las travesuras hechas en esta ocasión por el duende de las imprentas. Hay algunas erratas muy ortodoxas (el colofón está al revés, la elección de las capitulares parece muy desafortunada, los logotipos de la portada parecen hechos en la fotocopiadora de la esquina y la fecha de aparición original de los artículos se puso en un lugar que sugiere confusiones), pero hay una que en lo personal me divirtió mucho. Al revisar por primera vez el índice del libro, mis ojos se fijaron de manera casual en la referencia a un artículo llamado "Una lágrima por Prigione". Yo francamente nunca había sospechado que en el terreno de las aficiones personales, el doctor Latapí tuviera esas debilidades, pero con alivio, ya avanzada la lectura, descubrí que no había lágrimas ni lamentos, sino apenas una travesura más del infatigable duende, que al suprimir en el índice dos letras cambió por completo el sentido del título, que en realidad es "Ni una lágrima por Prigione".

Quisiera terminar mi comentario y mi invitación a la lectura de este nuevo libro de Pablo Latapí recordando unas reflexiones suyas sobre el valor y el sentido de la historia humana. En la escuela se nos enseñó que la historia patria es una sucesión interminable de actos de heroísmo y de hazañas inconmensurables. Las derrotas no se explican muy bien y las debilidades de los grandes hombres no merecen más que el piadoso silencio. Provistos de ese bagaje, no atinábamos a explicarnos la "docena trágica", ni mucho menos "el error de diciembre", la peculiar filosofía del dinero del "hermano incómodo" y sus millonarias transferencias a fondos de inversión radicados en paraísos fiscales, 
las increíbles historias de los banqueros convertidos en bandidos (y viceversa) o la rebelión de los indígenas chiapanecos, a los que se suponía beneficiarios principales del actual orden de cosas.

Más allá de la gran indignación que todos estos asuntos han provocado en muchísimos mexicanos, Latapí nos recuerda que la historia humana es siempre una combinación de luces y sombras. Leer la historia de México o pensar sobre estos últimos capítulos de los que somos testigos presenciales es transitar o echar brincos entre la desilusión y la esperanza. Lo que sucede puede resultar desesperante, pero nos queda el amargo y doloroso consuelo del aprendizaje y la certidumbre de que en lo futuro las cosas pueden ser de otro modo. Si vivir no es cumplir un designio sino labrarse un destino y encarar con valentía y optimismo el futuro, entonces tiene razón Hans Freyer, de quien Latapí cita estas palabras: "Quién sabe lo que quedaría de un hombre si no hubiera espera imprecisa, esperanza ni temor, sospecha ni deseo, ni tampoco, por tanto, presentimiento del futuro; si no hubiera recuerdo alguno ni añoranza de algo, ni gratitud, ni conciencia de los orígenes de nuestra actual existencia". ?3: 
